\title{
Using a GIS-based network analysis to determine urban greenspace accessibility for different ethnic and religious groups
}

\author{
Alexis Comber ${ }^{\mathrm{a}, *}$, Chris Brunsdon ${ }^{\mathrm{a}}$, Edmund Green ${ }^{\mathrm{b}, 1}$ \\ a Department of Geography, University of Leicester, Leicester LE1 7RH, UK \\ ${ }^{\mathrm{b}}$ Land and Biodiversity, Groundwork Trust for Leicester \& Leicestershire, Parkfield, Western Park, Leicester LE3 6HX, UK \\ Received 31 July 2007; received in revised form 15 November 2007; accepted 2 January 2008 \\ Available online 10 March 2008
}

\begin{abstract}
Greenspace access in an English city was analysed using a network analysis in a geographical information system (GIS). Access for different religious and ethnic groups was compared with benchmark standards that form part of the UK government guidance on greenspace provision. Despite having nearly more than twice the recommended amount of accessible greenspace per capita, its distribution and pattern show considerable variation especially when spatially analysed with respect to ethnic and religious groups. Whilst the specific results are locally important (Indian, Hindu and Sikh groups were found to have limited access to greenspace in the city), the study shows how a GIS-based network analysis in conjunction with statistical analysis of socio-economic data can be used to analyse the equity of access to community goods and services. The results can be used to inform the local planning process and the GIS approach can be expanded into other local authority domains. The approach presented in this paper offers a generic method for quantifying the differences in the provision of community goods and services (e.g. educational, health, environmental, etc.) for a range of different societal groups (e.g. related to deprivation, disability, occupation, economic activity, household tenure and types, age and health).
\end{abstract}

(C) 2008 Elsevier B.V. All rights reserved.

Keywords: Greenspace; GIS; Network analysis; Ethnicity; Religion; Urban planning

\section{Introduction}

This study analyses the provision of accessible urban greenspace in Leicester (a city in the English midlands) in relation to the distribution of ethnic and religious trends. It uses a geographical information system (GIS) to apply a network analysis of greenspace access. In this work the term 'greenspace' is used to signify natural greenspaces in an urban context. The typology of urban greenspaces for the UK as defined by the Urban Green Spaces Task Force (2002) and Handley et al. (2003a) is strictly adhered to. Handley et al. (2003a) note that a range of different land features can be considered as natural greenspaces in an urban context. This definition promotes the concept of multifunctional greenspaces, referencing criteria

\footnotetext{
* Corresponding author.

E-mail addresses: ajc36@le.ac.uk (A. Comber),cb179@le.ac.uk (C. Brunsdon), egreen@environ.org.uk (E. Green).

${ }^{1}$ NOW at: Derbyshire Wildlife Trust, East Mill, Bridge Foot, Belper, Derbyshire, DE56 1XH, UK.
}

for greenspace definition described in Harrison et al. (1995), and defining greenspace as including sites awaiting development and land alongside waterways tracts of 'ecapsulated countryside' often existing within formally designated open space. Handley et al. (2003a) (p. 4) state that "an area of managed parkland or playing fields could also be said to be natural, at least in part, if the appropriate criteria are met". Using this definition, urban greenspace includes many types of land in an urban setting from formally designated areas such as parks, areas set aside under legislation such as allotments, to more natural areas such as nature reserves and corridors along river banks. Such green areas account for around $14 \%$ of urban space nationally, though in Leicester the area accounts for approximately $25 \%$ of the city area. In 2004-2005, local authorities in the UK spent an estimated $£ 700$ million on maintaining and renovating urban greenspace as they have the key strategic role in ensuring sufficient local provision of good quality urban greenspace, although a number of other bodies, particularly housing associations may be responsible for managing elements of greenspace (National Audit Office, 2006). 


\section{Background}

\subsection{Greenspaces}

Contact with and access to nature is beneficial to the people's quality of life. English Nature (now Natural England) provides a set of standards for evaluating the provision of and access to natural places, Accessible Natural Greenspace Standards (ANGSt). The standards originate from work by Harrison et al. (1995) as described in Handley et al. (2003b) and English Nature's A Space for Nature (English Nature, 1996). These standards aim to provide benchmarks for assessing the provision of places where people can experience and enjoy nature and form a part of the UK government guidance on open space provision (Urban Green Spaces Task Force, 2002). They recommend that provision should be made of at least 2 ha of accessible natural greenspace per 1000 population according to four hierarchical levels. The ANGSt model specifies guidelines for greenspace access provision:

- No person should live more than $300 \mathrm{~m}$ from their nearest area of natural greenspace of at least 2 ha in size.

- There should be at least one accessible 20 ha site within $2 \mathrm{~km}$ from home.

- There should be one accessible 100 ha site within $5 \mathrm{~km}$.

- There should be one accessible 500 ha site within $10 \mathrm{~km}$.

The ANGSt model therefore specifies the provision of certain sizes of greenspaces within certain distances. It provides a standard against which local access (and developments which may change local access) can be compared. Handley et al. (2003b) describe how information on greenspace access can be used to set action priorities. They note that there may be different local factors that influence a hierarchy priorities involving spatial factors, ease of implementation (i.e. most gain for the least resource input) and what they call "special" priorities relating to specific local circumstances such as "tackling of social exclusion by enabling the greater use of accessible natural greenspace by the disabled, women or ethnic minorities" (Handley et al., 2003a, p. 27).

\subsection{Access to greenspaces}

There is concern that access to the countryside and urban greenspaces by different ethnic and religious groups is limited. Greenspaces provide important environmental facilities: they are a highly valued contact with nature (Kahn, 1999) and offer health benefits (Frumkin, 2001). Frumkin (2005), writing about access to greenspace in the US, noted that the activities and preferences of ethnic groups vary. Madge has noted that ethnic groups have different experiences of greenspaces, with some groups fearing dogs and racial attacks (Madge, 1997). Rishbeth (2001) described the relationships between the ethnicity and experience of countryside and greenspaces. Burgess et al. (1988) illustrated how Asian woman linked their experience of their native countryside to their pleasure of being in natural surroundings in Britain. Rishbeth and Finney (2006) con- sidered refugee attitudes to greenspaces in an emotive context, showing the potential importance of greenspaces in providing a conceptual link between former and new homes. They identified physical and psychological barriers to be overcome for the benefits of greenspace to be realised. Mackenzie and Paget (1999), commenting on the relationship that ethnic minorities have with the environment, concluded that they should be confident that they are participating fully in a society that included the "environment', countryside recreation and rural culture. However, the authors found that although some ethnic minorities, particularly the middle classes, were engaged in this countryside recreation and rural culture, the majority were not. Gobster (2002) examined the patterns and preferences in greenspace use amongst different ethnic groups in Chicago and found that ethnic minority users of greenspace travelled larger distances but visited them less frequently than white greenspace users. Aygeman (2001) offered some reflective observations on the involvement of ethnic minorities with emerging sustainable development initiatives and environmental justice discourses, noting that there has been much research into the tensions between ethnic minorities in Britain and the environmental movement. He argued that ethnic minorities in Britain are routinely short-changed by a systematic indifference to their environmental and planning needs, resulting in an image of environmentalism and the countryside as an exclusive white space. For instance, initiatives to enhance greenspaces increase may unintentionally increase adjacent residential property values and drive out residents of lower socio-economic status. Heynen et al. (2006) analysed the spatial distribution of urban greenspaces with income. They found a strong positive correlation between the amount of residential canopy cover and median household income and implied that any investment in greenspaces that was not carefully targeted would benefit the wealthy rather than the socio-economically deprived residential areas.

\subsection{Spatial analysis of greenspace access}

GIS offers a powerful set of tools for analysing spatial data. GIS have been used in a number of greenspace studies. Mahon and Miller (2003) used a GIS to identify greenspace with high ecological, recreational and aesthetic value in order to protect certain greenspace areas from development. Randall et al. (2003) presented a GIS-based decision support tool to model planning scenarios relating to the creation of new greenspace areas as part of neighbourhood greening strategies. Herbst and Herbst (2006) also described a GIS-based decision support tool to ascribe ecological and aesthetic value to greenspace sites for use in the planning process. Jim and Chen (2003) presented a threetiered approach for linking, developing and enhancing existing greenspace areas in the urban planning process. Their approach was to model the spatial characteristics of existing greenspace provision within a GIS and to use landscape metrics to quantify the connectivity and accessibility of proposed greenspace development. Jim and Chen (2006) conducted a survey-based study on the use of different types of greenspaces and the willingness to pay for access to them. Their results provided the basis of a cost model for greenspace development and more precise plan- 
ning of greenspace provision. Zhang and Wang (2006) presented a study that also used landscape metrics to quantify the spatial configuration of greenspaces and suggested GIS-based network analyses to analyse the accessibility of proposed greenspace enhancements.

GIS tools exist to model new greenspace developments, to quantify the value of different greenspaces, for scenario testing planning models and to quantify the spatial configuration of greenspace elements in the urban landscape. No studies exist that have analysed or quantified the provision of access to greenspace by different community groups in order to inform the planning process. Without careful targeting, taking the spatial distribution of ethnic and religious groups into account, it is difficult for initiatives that promote increased or equitable access to community goods and services such as greenspace to be effective. Whilst there has been much discursive and qualitative research on the access of different demographic groups to greenspace, the extent of this access has not been quantified: there have been no studies of actual access of the British population to urban greenspaces; there have been no studies of the actual access to greenspace by ethnic and religious groups. The work presented in this paper builds on the suggestions of Pauleit et al. (2003) who recommended that the planning process should include effective decision support models to overcome barriers to the adoption of English Nature's Accessible Natural Greenspace. This research was concerned not just with the spatial and demographic patterns associated with greenspace provision but also with the accessibility of that greenspace. It addressed the following questions in relation to the provision of accessible greenspace in Leicester:

- How is greenspace access related to ethnicity?

- How accessible are greenspaces for different religious groups?

- Which areas need to have greenspace provision enhanced?

Analysing accessible greenspace addresses a gap in the research and demonstrates how a relatively simple spatial analytical tool, network analysis, can be used in conjunction with demographic data to quantify access to accessible greenspace by different communities.

\section{Method}

\subsection{Study area}

Leicester is in the English midlands and has a large and diverse ethnic minority population. The 2001 census estimated that $36 \%$ of Leicester's population to be from an ethnic minority background with $30 \%$ having an Asian background. They are mainly Indians from either East Africa or from Gujarat in India $(26 \%)$ with smaller Bangladeshi (1\%) and Pakistani (1.5\%) communities. The black population in Leicester comprises two groups-those of West Indian origin $(1.7 \%)$ and those of African origin (1.2\%), including in the last 6 years a significant number from Somalia. Many of the Somali communities are European Union nationals. The 2001 census lists the faith communities in Leicester as being Christian
(45\%), Hindu (15\%), Muslim (11\%) and Sikh (4\%) (see The Diversity of Leicester: A Demographic Profile-available from http://www.leicesterpartnership.org.uk/Meetings/Executive/ Meet190706/AA\%20LATEST\%20DRAFT\%20Diversity \%20of\%20Leicester\%20\%2024\%20May\%20062.pdf.

\subsection{Population census data}

In order to quantify and measure the access to greenspaces by different ethnic and religious groups, a network analysis was performed to measure distances between greenspace access points and the centres of 2001 population census output areas (Martin, 1998). Output area polygons are constructed from clusters of adjacent postcodes. They were designed to have similar population sizes and to be as socially homogenous as possible, based on tenure of household and dwelling type. Output areas provide a spatially fine unit of data analysis: they are the smallest scale at which census data are reported and are the building block from which all other higher level census geographies are formed. They contain a mean population of 300 persons. A full description of the design of output areas is provided by Martin (1998) and the ONS website (see http://www.statistics.gov.uk/ geography/downloads/georoadshowpaper.pdf). The 2001 census reports information about ethnicity and religious identity. In the ethnic group section there are two levels. Level 1 is a coarse classification into five main ethnic groups. Level 2 nests within Level 1, and provides a finer classification (22 groups). Data was collected on religion and respondents were able to indicate whether they considered themselves to be Christian, Buddhist, Hindu, Jewish, Muslim, Sikh or Any other religion, No religion, or Religion not stated. The distributions of the three major ethnic groups are shown in Fig. 1 and the four religious groups (and atheists) are shown in Fig. 2.

\subsection{Data preparation and network analysis}

Network analyses can answer a range of questions related to linear networks such as roads, railways, rivers, facilities and utilities. This spatial analysis technique uses network data (usually linear features such as roads, footpaths) to calculate distances between points or nodes on the network. This approach underpins the satellite navigation systems found in many cars. Common applications are route finding, route planning, identifying the closest facility by travel time or distance, calculation of service areas (e.g. areas within 10 minute's walk of a bus stop), etc. There are various ways of parameterising the analysis based on typical road speeds, blockages, and minimising the use of smaller or remote parts of the network depending on the task. In this work, the network analysis was undertaken using SANET (Okabe et al., 2006). Alternative techniques include buffering and point-to-point straight line distance calculation, but these generate an over-simplistic analysis of access, taking no account of actual access routes (e.g. via path and roads) and barriers (e.g. rivers, railways). In their review of the ANGSt model, Handley et al. (2003a) illustrated how a GIS analysis could be used to evaluate access. They noted that in the implementation of a study of access, a network analysis offered the optimal method for eval- 


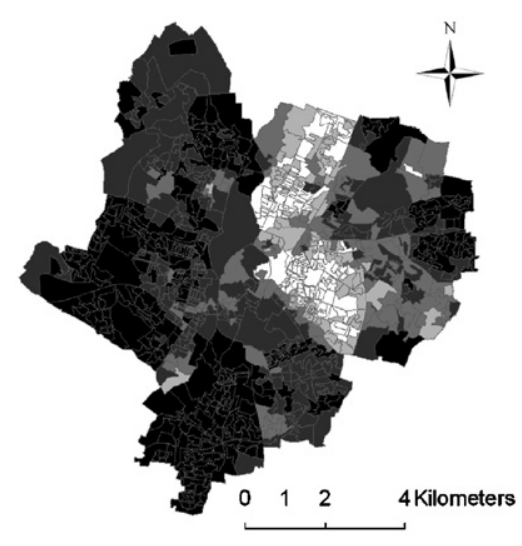

British

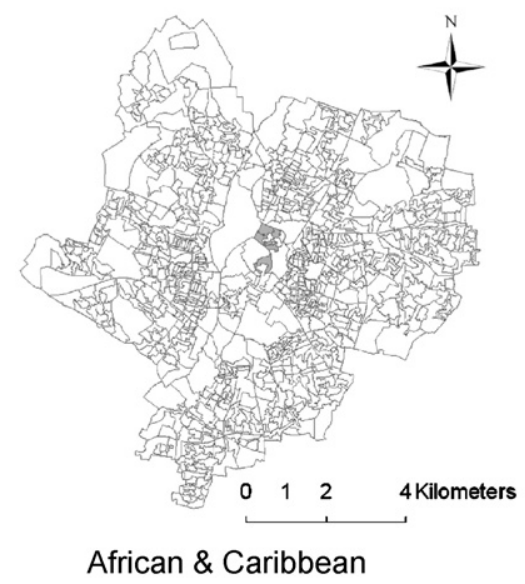

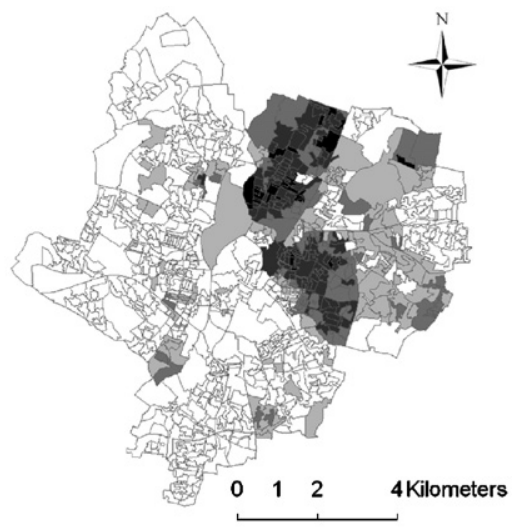

Indian

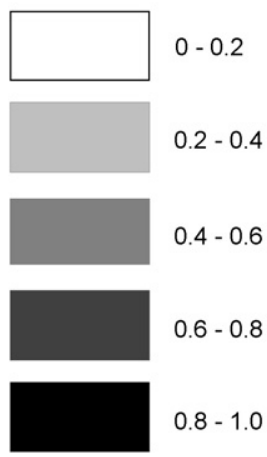

Proportions of the population

Fig. 1. The proportions of different ethnic groups in Leicester.

uation as it calculates the actual distance from site access points (i.e. is more accurate analysis than other methods) and reveals a more realistic picture of site catchment zones. Network analysis involved the following stages:

(1) Digitising the greenspace access points.

(2) Creating Output Areas centroids.

(3) Calculating the distances between the access points and output area centres.

(4) For each output area, calculating the distance to each greenspace and storing it in a database.

(5) Analysing of the database for access to greenspaces and in terms of the ethnic and religious make up of each output area.

The greenspace data were provided by Leicester City Council via the Groundwork Trust for Leicester \& Leicestershire (GWLL, previously called 'Environ'). The data included used for analyses were:

- Parks and public gardens.

- Green corridors (e.g. adjacent to rivers and canals);

- Local Nature Reserves.

- Surviving Urban Commons;
- Spinneys (or small areas of woodland with undergrowth);

- Sites of importance for nature conservation.

- Washland areas (i.e. regularly flooded areas near to rivers).

- Cemeteries.

Golf course, agricultural land, school playing fields and allotments were excluded from the analysis, as these are not accessible to the general public for everyday use. Also omitted were historic churchyards all of which were less than 1 ha in area as these are below the areas specified in the ANGSt model. The roads data was extracted from OS Meridian $2(1: 50,000)$, the output area polygons were provided by the Office of National Statistics and the output area census data were downloaded from Casweb (http://www.census.ac.uk/casweb/).

Network analysis is often concerned with determining the supply and demand of some resource. The access points for greenspace access were manually digitised using OS 1:50,000 scale colour raster data and were placed inside the greenspace area as shown in Fig. 3. Nodes to represent the supply (access points to the greenspaces) and the demand (the locations of the output areas) were inserted into the line network prior to running the network analysis. Fig. 4 shows the insertion of an output area centroid and greenspace access points as nodes into the network by way of example. The algorithm that computed the output 
area centre did so using its envelope or the rectangular window that it is contained by. The use of centroids as the location for output areas is commonly used for GIS analyses that seek to relate polygon-based objects to linear networks. For some subareas of the polygon, the actual distance will be over-estimated and for others it will under-estimated. This is a problem for analyses that use census data geographies where an assumption of within output area heterogeneity has to be made. In this case we are confident that any uncertainty are due to under and over estimation are negligible due to there being 890 output areas with each output area representing $\sim 300$ people. In this analysis we have assumed that these losses and gains balance each other out over 890 output areas and 52 greenspaces.

\section{Results}

The results describe access to greenspaces for different religious and ethnic communities in Leicester. The definition of greenspace is from the typology of urban greenspace for the UK defined by the Urban Green Spaces Task Force (2002) and

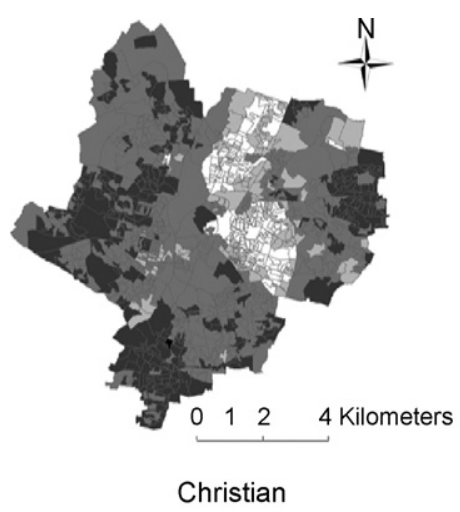

Christian

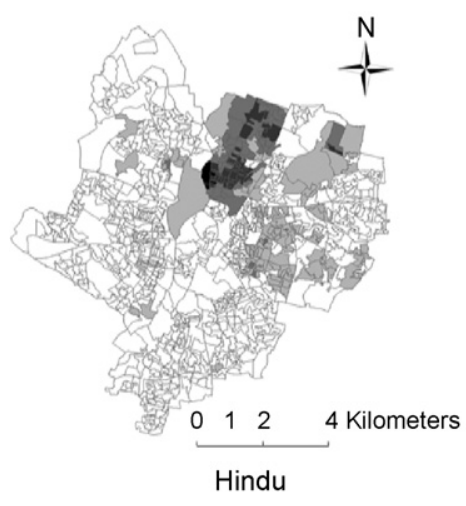

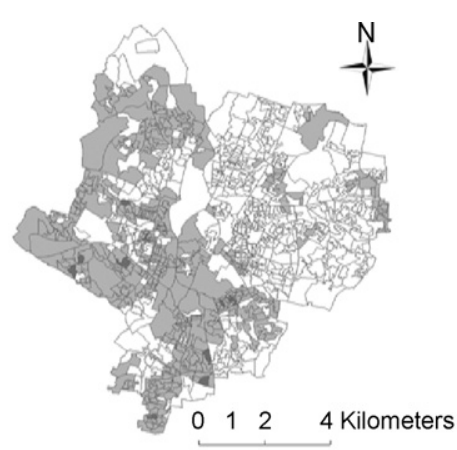

Atheist

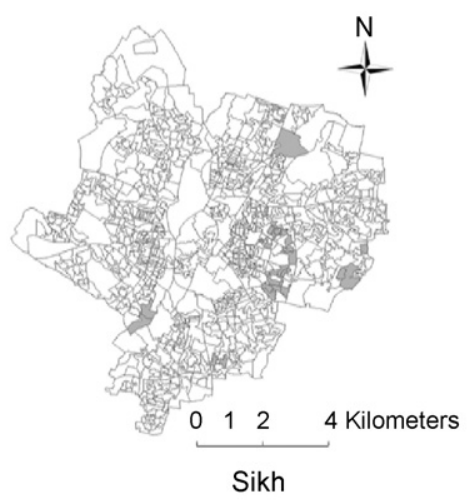

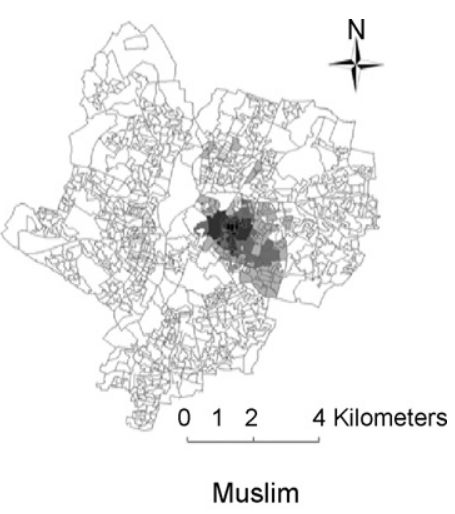

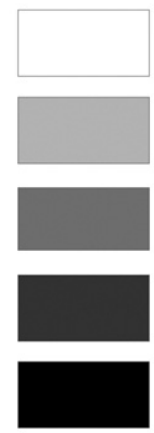

$0-0.2$

$0.2-0.4$

$0.4-0.6$

$0.6-0.8$

$0.8-1.0$

Proportions of the population

Fig. 2. The distribution of the major religious groups in Leicester.
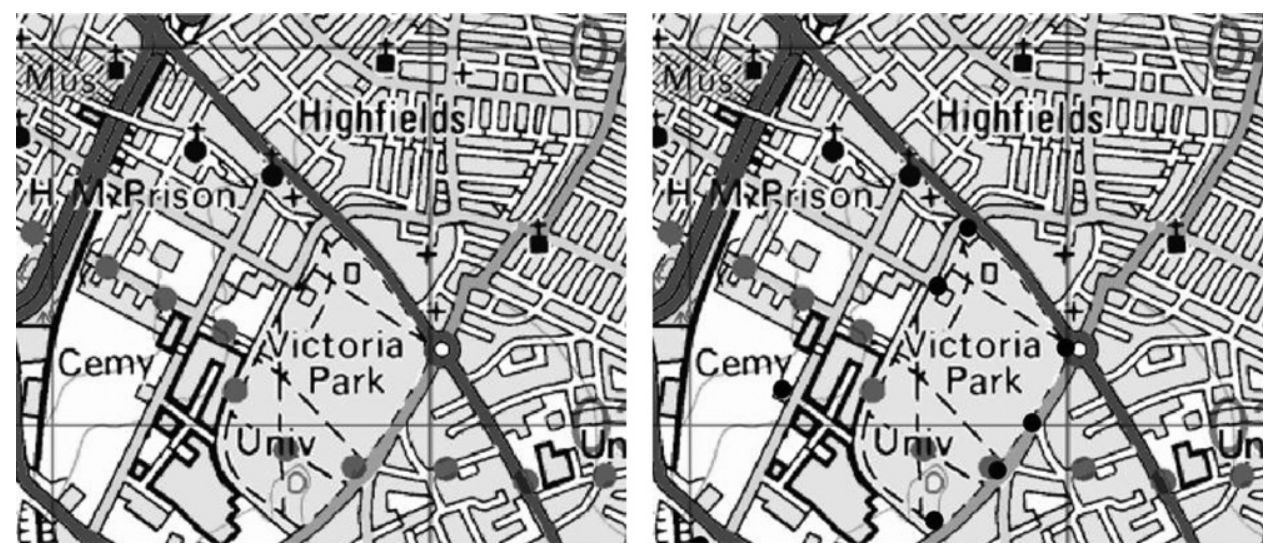

Fig. 3. An example of greenspace (left) and the manual insertion of access points (right), basemap @Crown Copyright/database right 2007, an Ordnance Survey/EDINA supplied service (scale from the basemap-each square is $1 \mathrm{~km}^{2}$ ). 
described in Handley et al. (2003a) for the analysis of ANGSt model.

\subsection{Access to greenspace}

English Nature/Natural England has published guidelines on the provision of accessible greenspace and these provide the basis for assessing access in Leicester. The simplest of these to evaluate is "there should be 2 ha of accessible natural greenspace per 1000 population". The greenspace in Leicester is illustrated in Fig. 5. Taking this as a simple statement of greenspace provision per capita population using the data analysed, Leicester does very well as there is almost double the amount of greenspace land. Leicester's population is approx- imately 280,000. The total greenspace area is 980 ha. This produces a figure of 3.5 ha per 1000 population.

Other ANGSt model recommendations specifies further guidelines for provision of and access to greenspaces:

- "no person should live more than $300 \mathrm{~m}$ from their nearest area of natural greenspace of at least 2 ha in size" (Rule 1);

- "there should be at least one accessible 20 ha site within $2 \mathrm{~km}$ from home" (Rule 2);

- "there should be one accessible 100 ha site within 5 km" (Rule 3); and

- "there should be one accessible 500 ha site within $10 \mathrm{~km}$ " (Rule 4).
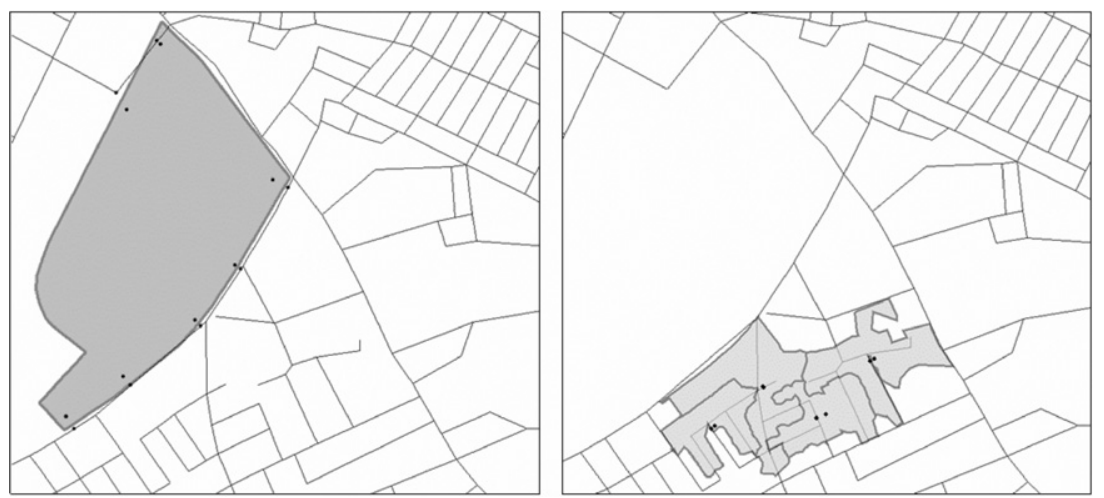

Fig. 4. An example greenspace access points (left) and output areas centroids (right) inserted into a road network (scale from Fig. 3).

Table 1

Proportions of different religious and ethnic groups without access to different classes of greenspaces

\begin{tabular}{|c|c|c|c|c|c|}
\hline & & Population & Rule $1(\%)$ & Rule $2(\%)$ & Rule $3(\%)$ \\
\hline \multirow[t]{7}{*}{ Religious } & Total & $2,79,933$ & 89.7 & 39.9 & 5.4 \\
\hline & Christian & $1,25,187$ & 90.5 & 39.0 & 7.2 \\
\hline & Buddhist & 636 & 86.8 & 22.6 & 1.9 \\
\hline & Jewish & 427 & 89.0 & 18.5 & 6.3 \\
\hline & Muslim & 30,879 & 83.3 & 28.7 & 1.9 \\
\hline & Sikh & 11,806 & 92.2 & 45.3 & 7.5 \\
\hline & Religion not stated & 19,782 & 90.4 & 37.4 & 4.6 \\
\hline \multirow[t]{12}{*}{ Ethnic } & Total & $2,79,832$ & 89.7 & 39.9 & 5.4 \\
\hline & British & $1,69,456$ & 90.3 & 37.1 & 6.6 \\
\hline & Irish & 3561 & 89.0 & 40.0 & 5.6 \\
\hline & Other White & 5676 & 90.6 & 27.5 & 4.3 \\
\hline & Pakistani & 4285 & 84.9 & 34.7 & 3.7 \\
\hline & Bangladeshi & 1929 & 81.1 & 13.4 & 1.3 \\
\hline & Other Asian & 5493 & 90.0 & 41.6 & 2.9 \\
\hline & Caribbean & 4615 & 91.5 & 37.0 & 2.9 \\
\hline & African & 3418 & 90.6 & 32.8 & 2.5 \\
\hline & Other Black & 543 & 94.1 & 44.4 & 2.8 \\
\hline & Chinese & 1402 & 87.2 & 17.6 & 2.4 \\
\hline & Other Ethnic Group & 902 & 88.8 & 31.2 & 1.6 \\
\hline
\end{tabular}




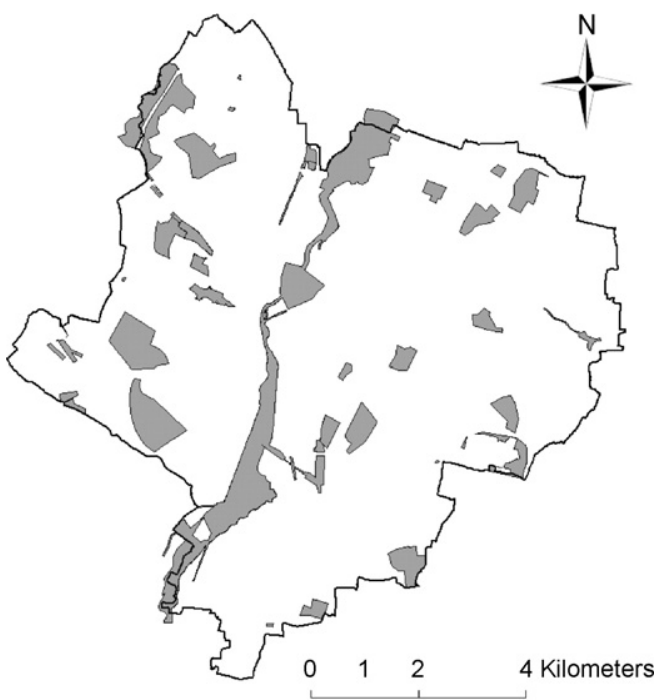

Fig. 5. The distribution of greenspace areas in Leicester.

Table 1 shows the results of applying a network analysis to the distribution of the supply of greenspace data, in relation to the spatial distribution of the demand of the census data at the output area level (the finest scale freely available).

- 2 ha within $300 \mathrm{~m}$ : The majority of the population (89.7\%) in Leicester lack provision of small, local greenspaces less than $300 \mathrm{~m}$ from their homes (Rule 1) as defined under the ANGSt model for greenspace access and how it should be implemented in an urban context by Handley et al. (2003a,b) - see Fig. 6a. This lack of provision is relatively uniform across ethnic and religious groups (Table 1), where the proportions of the population access to such greenspaces are similar.

- 2 ha within $2 \mathrm{~km}$ : Access to 20 ha sites within $2 \mathrm{~km}$ (Rule 2) is more variable, with areas in the east and south west have access to more than one 20 ha greenspace-see Fig. 6 b. Across the whole of Leicester, $39.9 \%$ of the population does not have access to such sites and there is considerable spatial variation in access amongst religious and ethnic groups. In the south and central-east there is no access to such sites and the distribution of access to 20 ha sites to large sections of Indian, Hindu and Sikh groups is restricted (Table 1).

- 100 ha within $5 \mathrm{~km}$ : Most of the city has access to 100 ha sites (Rule 3) - see Fig. 6c, although where there is lack of access, Asian and black communities are more affected (Table 1).

- $500 \mathrm{ha}$ within $10 \mathrm{~km}$ : There are no 500 ha sites in Leicester (Rule 4), although they exist outside the city boundaries-see Section 5 .

The distribution of greenspace access for Rules 1 and 3 is even across the city and Rule 4 cannot be tested. There is much more variation and interaction amongst ethnic and religious groups for Rule 2 ("there should be at least one accessible 20 ha site within $2 \mathrm{~km}$ from home"). Mosaic plots offer a convenient method to analyse and visualise the differences between the predicted and observed values in Table 1 . Mosaic plots were proposed by Hartigan and Kleiner (1981) and extended by Friendly (1994). Mosaic plots visualise standardised residuals (often referred to as a standard normal distribution) of a loglinear model and in this example we have used the shade, hatching and outline of the mosaic's tiles to do this. The plots show the access to greenspace in terms of Rule 2 ( 20 ha within $2 \mathrm{~km}$ ) for different ethnic groups (Fig. 7) and religious groups (Fig. 8) and the tile areas are proportional to the numbers of people affected. Negative residuals are shaded and with broken outlines and positive ones are hatched with solid outlines.

The plots show which groups are under- or over-represented. The hatched tiles show combinations of access and religion or ethnicity that are higher than average. The tiles with crossed hatch correspond to combinations of access and ethnicity or religion whose residuals are greater than +4 , when compared to a model of proportional equal levels of access for all ethnicities (or religions). This indicates a much greater frequency in those cells than would be found if this model were true (i.e. was un-biased and equitable). The dark shaded tiles correspond to the residuals less than -4 indicating significantly much lower frequencies than would be expected. The mosaic plots show that the ethnic group 'Indian' and the religious groups 'Sikh' 'Hindu' have less greenspace access than would be expected under assumptions of equitable and even access. Other ethnicities and religions have about average levels of access or more than expected. Of note are that Muslims and those of No Stated Religion have more access than would be expected. The mosaic plots are able to summarise different dimensions of the results simultaneously: in this instance the mosaic tiles show the relative populations of the different religious and ethnic groups and thus their relative importance of the results. For example, the lack of access for the ethnicities of 'Mixed 2' (White and Black African in Table 1) and 'Other Black' are also higher than expected but the numbers for these groups in Leicester are low, making any statement about the results for these small numbers of people ( $\sim 550$ in each case) irrelevant.

The data in Table 1 relating to Rule 2 were further analysed in order to assess the relative equity of access amongst different societal groups. The numbers of people with and without access to Rule 2 greenspace in each census area were summed for the different classes contained within the census attributes of religion and ethnicity. Generalised linear models were used to estimate likelihood of access as a function of either religion or ethnicity. A table of counts was drawn up where the rows designated whether individuals had access to greenspace (under Rule 2) and the columns designated either the religion or the ethnicity of individuals. The count in column $i$ and row $j$ is denoted by $c_{i j}$. To test whether there is an association between the row and column effects, the Poisson regression model was applied:

$E\left(c_{i j}\right)=\log \left(r+A_{i}+F_{j}\right)$

where $c_{i j}$ has a Poisson distribution, $r$ is an intercept term, $A_{i}$ is a column effect and $F_{j}$ is a row effect, is compared 


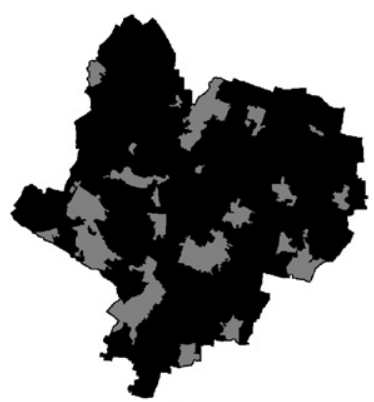

(a)

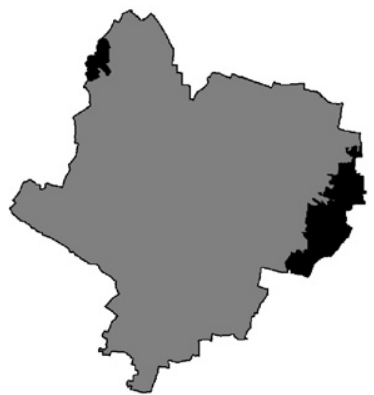

(c)

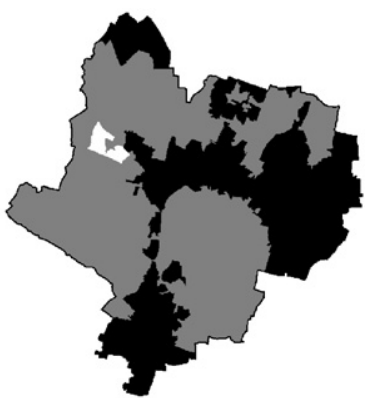

(b)

Kilometers

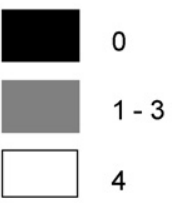

Number of accessible greenspaces

Fig. 6. The distribution of access to greenspaces in Leicester in Leicester (a) Rule 1, (b) Rule 2 and (c) Rule 3.

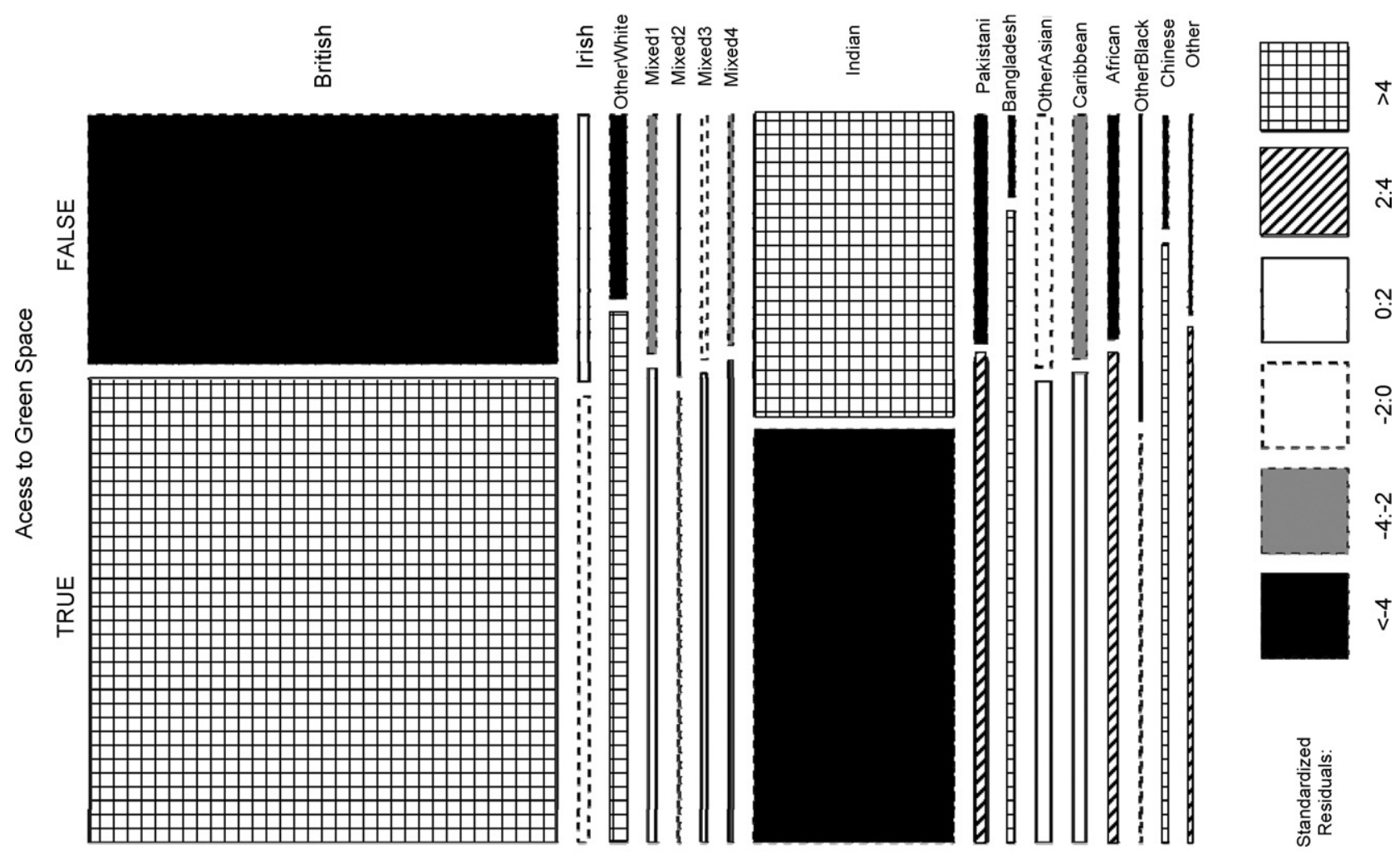

Fig. 7. The mosaic plot of access (“True”) to greenspace by ethnicity. Mixed 1 is 'White and Black Caribbean', Mixed 2 is 'White and Black African', Mixed 3 is 'White and Asian' and Mixed 4 is 'Other Mixed'. 


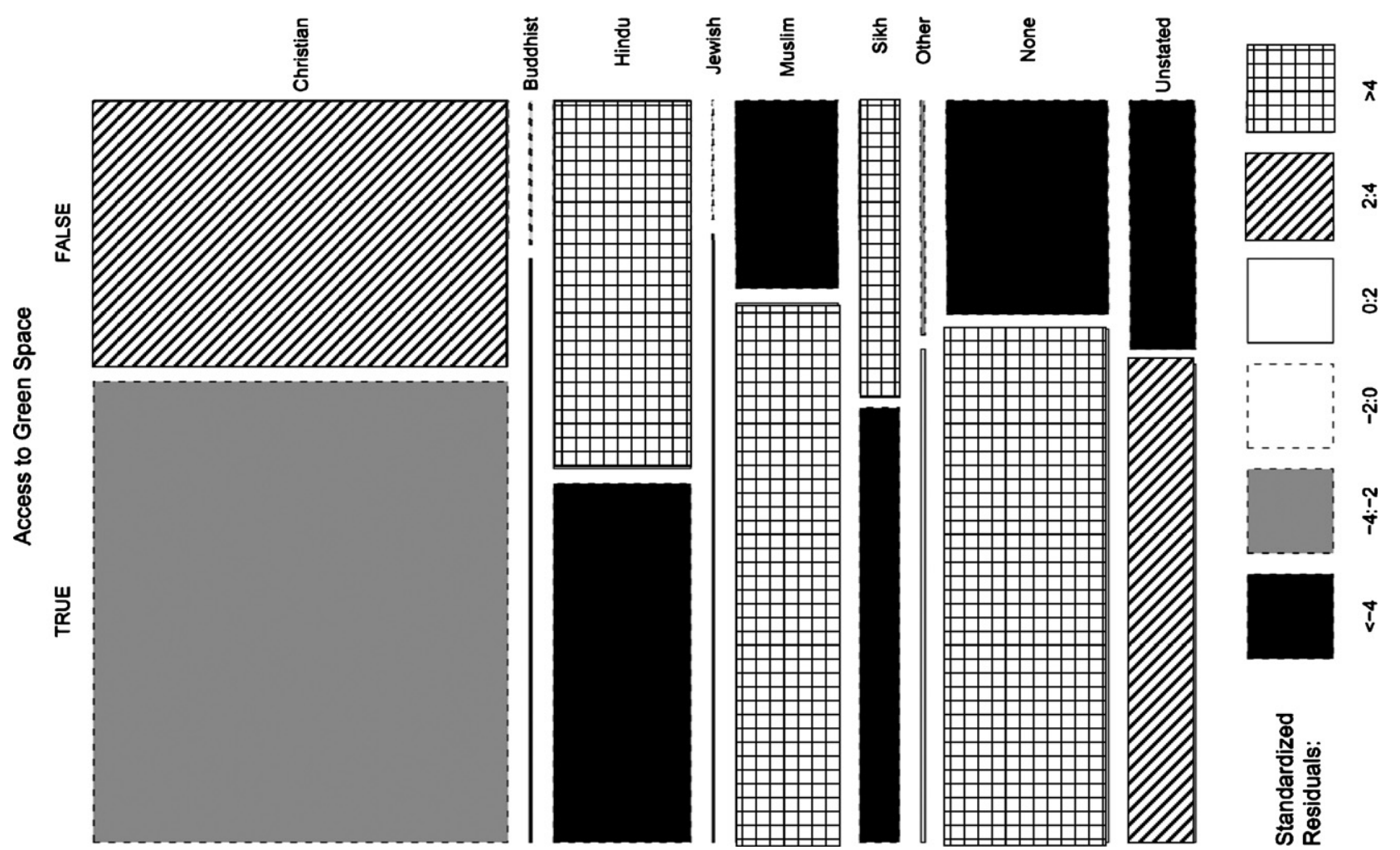

Fig. 8. Mosaicplot of access ("True") to greenspace by religion.

against the model:

$E\left(c_{i j}\right)=\log \left(r+A_{i}+F_{j}+I_{i j}\right)$

where the extra term $I_{i j}$ is an interaction effect between rows and columns. If this is significantly different from zero, this suggests some degree of association between the row and column effects. In this study, it may be used to test for association between either religion or ethnicity and access to greenspace. The counts as described above were cross-tabulated for the different classes of religion and ethnicity (Tables 2 and 3 respectively).

Values of $I_{i j}$ were estimated by fitting Eq. (2) to the data for religion and for ethnicity using the $R$ statistical software package These coefficients were related to a comparative index of access for each of the row categories, using the formula:

Access $=100\left(\exp \left(I_{i j}\right)-1\right)$

Table 2

The numbers of people of different religions with $(<2 \mathrm{~km})$ and without $(>2 \mathrm{~km})$ access to greenspace greater than 20 ha

\begin{tabular}{lrr}
\hline Census religion class & Access & No access \\
\hline Buddhist & 126 & 510 \\
Christian & 45,882 & 79,305 \\
Hindu & 20,907 & 20,341 \\
Jewish & 70 & 357 \\
Muslim & 7987 & 22,892 \\
No Religion & 14,361 & 34,428 \\
Any other religion & 380 & 799 \\
Sikh & 4756 & 7050 \\
Religion not stated & 6778 & 13,004 \\
\hline
\end{tabular}

Due to the way the interaction terms are calibrated, this quantity compares each column category $j$ against a 'reference' category. A value of 0 suggests the likelihood of access for category $j$ is the same as for the reference category. A value of +50 for category $j$ suggests access is one-and-a-half times as likely as the reference category, a value of -50 that it is half as likely, and so on. The reference categories for ethnicity and religion are 'British' and 'Christian' respectively.

For each of the coefficients, the access was calculated. The results for religion and ethnicity are shown in Tables 4 and 5 respectively.

Table 3

The numbers of people of different ethnic groups with $(<2 \mathrm{~km})$ and without $(>2 \mathrm{~km})$ access to greenspace greater than $20 \mathrm{ha}$

\begin{tabular}{lrr}
\hline Census ethnicity class & Access & No access \\
\hline African & 1073 & 2345 \\
Bangladesh & 219 & 1710 \\
British & 59,015 & $1,10,441$ \\
Caribbean & 1575 & 3040 \\
Chinese & 222 & 1180 \\
Indian & 30,278 & 41,755 \\
Irish & 1328 & 2233 \\
White and Black Caribbean & 953 & 1899 \\
White and Black African & 204 & 353 \\
White and Asian & 649 & 1249 \\
Other mixed & 391 & 821 \\
Other & 252 & 650 \\
Other Asian & 1936 & 3557 \\
Other Black & 232 & 311 \\
Other White & 1459 & 4217 \\
Pakistani & 1370 & 2915 \\
\hline
\end{tabular}


Table 4

Percentage access to greenspace (within $2 \mathrm{~km}$ of a 20 ha site) of different ethnic groups in an English city

\begin{tabular}{lc}
\hline Religion & Access (\%) \\
\hline Buddhist & 134.2 \\
Hindu & -43.7 \\
Jewish & 195.1 \\
Muslim & 65.8 \\
Sikh & -14.2 \\
Any other religion & 21.6 \\
No religion & 38.7 \\
Religion not stated & 11.0 \\
\hline
\end{tabular}

*Compared to the class 'Christians'.

The results show the elative equity of access amongst different religious and ethnic groups, as described in the UK 2001 census data in this case. The results quantify the extent to which each group has access to greenspace. For example, Hindus have $44 \%$ less access to greenspace than Christians. Similarly, Bangladeshis have $317 \%$ more access to greenspace than people who declared themselves to be British in the 2001 census.

In summary, despite much accessible greenspace in Leicester it is not evenly distributed. A number of statements about the provision of greenspace in Leicester can be made:

- Most of the population (90\%) lack access to 2 ha greenspaces within $300 \mathrm{~m}$.

- Most of Leicester has access to more than one site of 100 ha within $5 \mathrm{~km}$.

- $40 \%$ of Leicester residents lack access to 20 ha greenspace sites within $2 \mathrm{~km}$.

- Indian and Hindu and Sikh groups have significantly less access to these sites than other groups.

Table 5

Percentage access to greenspace (within $2 \mathrm{~km}$ of a 20 ha site) of different religious groups in an English city

\begin{tabular}{lc}
\hline Ethnicity & Access (\%) \\
\hline Irish & -10.1 \\
Other White & 54.4 \\
White and Black Caribbean & 6.5 \\
White and Black African & -7.5 \\
White and Asian & 2.8 \\
Other mixed & 12.2 \\
Indian & -26.3 \\
Pakistani & 13.7 \\
Bangladeshi & 317.2 \\
Other Asian & -1.8 \\
Caribbean & 3.1 \\
African & 16.8 \\
Other Black & -28.4 \\
Chinese & 184.0 \\
Other Ethnic Group & 37.8
\end{tabular}

*Compared to the class 'British'.

\section{Discussion}

This work has analysed access to greenspace in light of the ANGSt guidelines using the definition of greenspace provided by the Urban Green Spaces Task Force (2002) and described in Handley et al. (2003b). The results of this study show that, whilst at a superficial level Leicester is well provided for in terms of greenspace ( 3.5 ha per 1000 population), the distribution and access to certain categories of greenspace, as defined by the implementation of ANGSt in Handley et al. (2003b), is uneven. Overall, the city lacks access to small (at least 2 ha) greenspace that are easily accessible (i.e. with $300 \mathrm{~m}$ ). Access to sites greater than 20 ha within $2 \mathrm{~km}$ is variable and when these results are analysed in relation to the distributions of different religious and ethnic groups, certain groups are shown to be more disadvantaged than others. Out of the total population only $40 \%$ have access to such sites (Fig. 6b). Limited access is found in areas with high populations of Indians, Hindus and Sikhs.

This analysis used a network approach (Okabe et al., 2006) to quantify access to greenspace from the centres of polygons representing 2001 population census geographies. Points of access to individual greenspaces were identified from Ordnance Survey 1:25,000 base mapping. There are some important methodological issues and assumptions that warrant discussion. First, the analysis does not include any data from outside of the city. The presence of any greenspaces outside of the city would affect the results relative to the access distances for the different categories of greenspace. For instance, the picture of local access $(<300 \mathrm{~m})$ may be improved but only for those areas within that distance of the edge of the city. However, the greenspace areas are those for which the local authority is responsible. The analysis could be refined to accommodate such areas which although it may change the numbers of people affected for Rules 2 and 3 (20 ha within $2 \mathrm{~km}$ and 100 ha within $5 \mathrm{~km}$ ) it would not affect the proportional distribution of those affected in different ethnic and religious groups. Second, this study sought to determine access to land that was truly accessible to the public. For this reason only greenspaces that were 'accessible' to the public on an everyday basis were analysed. Private greenspaces and greenspaces with restricted access such as allotments, private farm land, golf courses and school playing fields were excluded.

The analysis explored in greater depth the results for 'Rule 2', relating to 20 ha sites within $2 \mathrm{~km}$, as these showed the most variation and inequitable access amongst different societal groups. It is to be hoped that these results will cause those responsible for town planning to consider undertaking spatial analyses of data for their areas of responsibility in order to characterise the equitability of the provision of community goods and services. This work should encourage the urban planning research community to consider GIS-based network analyses rather than using straight line or buffer distances as they offer a more realistic insight into actual provision and are able to reliably identify gaps in the provision of greenspace to inform the local planning process. For instance one consequence of this analysis on local decision making or the evaluation of new development proposals is to identify the areas that require enhanced greenspace provision according to the ANGSt guidelines. 
The options for addressing current gaps in the provision of greenspaces are not without problems themselves. For example, the Fig. 6a shows that Leicester does not have enough small local sites as defined by the ANGSt model implementation in Handley et al. (2003a) in Fig. 6a and those responsible for new developments may decide to include small public greenspace areas such as gardens and parks. It might be reasonable for initiatives and resources to be targeted at specific geographic areas within Leicester, at specific ethnic groups, particularly the Indian community and at specific religious groups (Hindu and Sikh communities). However, other research shows that where greenspaces are increased in targeted areas, the knock on effect is to inadvertently increase property values and drive out residents of lower socio-economic status (Heynen et al., 2006). A further aspect of this issue relates to the areas that immigrant communities settle and their pattern of settlement. There is much research that considers the dynamics of how population groups coalesce ranging from the Diaspora literature to the artificial life community (e.g. Schelling, 1969). For economic reasons, they may initially settle in older urban neighbourhoods that have more affordable housing but have less greenspace. The resolution of the disparities of access between different groups is complex. It is not the intention of this work to address this aspect of urban planning. Rather it aims to present a method for quantifying the extent of the problem as a baseline analysis of the existent situation.

The method presented in this paper, combining network analyses with statistical analysis of geo-demographic data, has a number of distinct advantages over approaches based on aggregations (e.g. the number of some service per 1000 population) or on access using straight line distances. First this approach quantifies actual access distances using road data rather than inferred ones using buffers or straight line distances. Second, the demographic data (in this case from the census) provides quantifies access for different classes of people in this case relating to ethnicity and religion. Third, this type of analysis is readily implemented inside standard GIS and statistical software and does not require expertise beyond those found in local authority GIS departments. Fourth, this work can be extended to use a wide variety of demographic data, including other census variables (deprivation, disability, occupation, economic activity, household tenure and types, age and health) and other geographies such as detailed geodemographic data at household or post-code level. Fifth, this analysis can be thematically extended to consider some wider issues relating to access such as travel times to different services and accessibility modelled by analysing public transport provision. This embraces a much wider concept of 'access' that relates to individual people and therefore includes transport (car ownership and public transport to/from individual greenspace sites) which in turn will relate to demographic features such as age (e.g. children travelling to greenspace by themselves). Sixth, as yet there has no study of actual accessibility to greenspace sites for the whole population let alone for different groups of people and this approach would allow the differences between different geographic areas to be compared.

Future work will compare the results with those from other cities in the region to quantify regional urban greenspace access and provision. The statistical analysis will be extended by developing regression techniques to explore how access relates to other socio-economic variables such as indices of deprivation, unemployment, house prices and house floor area. Other areas for future work include incorporating the mechanisms that result in certain ethnic groups living far away from greenspaces, and examining the determinants of the level of use of greenspaces by different sectors of society (i.e. the frequency of greenspace use) in order to understand why members of some ethnic groups are not participating in outdoor recreational pursuits.

\section{Conclusions}

This work has shown that the spatial distribution of access to greenspace is uneven amongst different groups of society in an English city. This analysis is novel and fills a gap in the urban planning literature, especially in relation to local planning: there has been no work that has quantified greenspace access for different ethnic and religious groups. We have presented a method for quantifying the size and spatial distribution of greenspace access using a GIS network analysis and census data to quantify access for different societal groups. The results may confirm intuitively known relationships which have not been quantitatively analysed. This work enables such hypotheses to be quantitatively confirmed and the approach enables decision-makers to identify which type of greenspace access is most lacking and where community access can be improved. However, for the results of this kind of analysis to implement, they need to be combined and augmented with qualitative local research into the needs of different groups, whose needs and perceptions of greenspace may vary.

The approach presented in this paper of combining GIS-based network analyses with regression approaches to socio-economic data offers a generic method for quantifying the differences in the provision of community goods and services (e.g. educational, health, environmental, etc.). It provides a starting point for further analyses at a range of geographies (e.g. national, regional) and provides a mechanism to asses the spatial distribution of access for a range of different groups (e.g. deprivation, disability, occupation, economic activity, household tenure and types, age and health). We hope that the method presented in this study will inform the ongoing discussions and research relating to local planning processes and demonstrates how GIS and spatial analyses can be used to quantify the provision of and access to a range of community goods and services amongst different socio-economic groups.

\section{Acknowledgements}

The authors would like to thank Groundwork Trust for Leicester \& Leicestershire and Leicester City Council for data the provision of greenspace data. Network analysis was performed using SANET (Okabe et al., 2006). The map data used was CCrown Copyright/database right 2007, an Ordnance Survey/EDINA supplied service. The authors would also like 
to thank the anonymous reviewers whose comments greatly improved the original draft.

\section{References}

Aygeman, J., 2001. Ethnic minorities in Britain: short change, systematic indifference and sustainable development. J. Environ. Policy Plan. 3, 1530 .

Burgess, J., Harrison, C.M., Limb, M., 1988. People, parks and the urban green: a study of popular meaning and values for open spaces in the city. Urban Stud. 25, 455-473.

English Nature, 1996. A Space for Nature. English Nature, Peterborough.

Friendly, M., 1994. Mosaic displays for multi-way contingency tables. J. Am. Stat. Assoc. 89, 190-200.

Frumkin, H., 2001. Beyond toxicity: the greening of environmental health. Am. J. Prev. Med. 20, 47-53.

Frumkin, H., 2005. Health, equity, and the built environment. Environ. Health Perspect. 113 (5), 290-291.

Gobster, P.H., 2002. Managing urban parks for a racially and ethnically diverse clientele. Leisure Sci. 24 (2), 143-159.

Handley, J., Pauleit, S., Slinn, P., Lindley, S., Baker, M., Barber, A., Jones, C., 2003a. Providing accessible natural greenspace in towns and cities: a practical guide to assessing the resource and implementing local standards for provision. http://www.englishnature.org.uk/pubs/publication/PDF/Accessgreenspace.pdf (available 15th January 2007).

Handley, J., Pauleit, S., Slinn, P., Barber, A., Baker, M., Jones, C. Lindley, S., 2003b. Accessible natural green space standards in towns and cities: a review and toolkit for their implementation. English Nature Report Number 526, Peterborough.

Harrison, C, Burgess, J, Millward, A and Dawe, G, 1995. Accessible natural greenspace in towns and cities: A review of appropriate size anddistance criteria, English Nature Research Report Number153. English Nature, Peterborough.

Hartigan, J.A., Kleiner, B., 1981. Mosaics for contingency tables. In: Eddy, W.F. (Ed.), Computer Science and Statistics: Proceedings of the 13th Symposium on the Interface. Springer-Verlag, New York.

Herbst, H., Herbst, V., 2006. The development of an evaluation method using a geographic information system to determine the importance of wasteland sites as urban wildlife areas. Landscape Urban Plan. 77 (2006), 178-195.
Heynen, N., Perkins, H.A., Roy, P., 2006. The political ecology of uneven urban green space: the impact of political economy on race and ethnicity in producing environmental inequality in milwaukee. Urban Aff. Rev. 42, $3-25$.

Jim, C.Y., Chen, W.Y., 2006. Recreation-amenity use and contingent valuation of urban greenspaces in Guangzhou, China. Landscape Urban Plan. 75, 81-96.

Jim, C.Y., Chen, S.S., 2003. Comprehensive greenspace planning based on landscape ecology principles in compact Nanjing city, China. Landscape Urban Plan. 65, 95-116.

Kahn, P.H., 1999. The Human Relationship with Nature: Development and Culture. MIT Press, Cambridge, MA.

Mackenzie, A., Paget, G., 1999. Maximising Ethnic Minority Involvement in Environmental Activities. Groundwork Blackburn, Blackburn.

Madge, C., 1997. Public parks and the geography of fear. Tijdschrift voor Economische en Sociale Geografie 88 (3), 237-250.

Mahon, J.R., Miller, R.W., 2003. Identifying high-value greenspace prior to land development. J. Arboriculture 29 (1), 25-33.

Martin, D., 1998. 2001 Census output areas: from concept to prototype. Popul. Trends 94, 19-24.

National Audit Office, 2006. Enhancing Urban Green Space, Office of the Deputy Prime Minister. NAO Report (HC 935 2005-2006). http://www.nao.org.uk/publications/nao_reports/05-06/0506935.pdf (available 15th January 2007).

Okabe, A., Okunuki, K., Shiode, S., 2006. SANET: a toolbox for spatial analysis on a network. Geogr. Anal. 38, 57-66.

Pauleit, S., Slinn, P., Handley, J., Lindley, S., 2003. Promoting the Natural Greenstructure of Towns and Cities: English Nature's Accessible Natural Greenspace Standards Model. Built Environ. 29 (2), 157-170.

Randall, T.A., Churchill, C.J., Baetz, B.W., 2003. A GIS-based decision support system for neighbourhood greening. Environ. Plan. B: Plan. Des. 30 (4), 541-563.

Rishbeth, C., 2001. Ethnic minority groups and the design of public open space: an inclusive landscape? Landscape Res. 26 (4), 351-366.

Rishbeth, C., Finney, N., 2006. Novelty and nostalgia in urban greenspace: refugee perspectives. Tijdschrift voor Economische en Sociale Geografie 97 (3), 281-295.

Urban Green Spaces Task Force, 2002. Green Spaces, Better Places-Final report of the Urban Green Spaces Task Force. DTLR, London.

Zhang, L., Wang, H., 2006. Planning an ecological network of Xiamen Island (China) using landscape metrics and network analysis. Landscape Urban Plan. 78, 449-456. 